by heterozygosity for cystic fibrosis would confer biological advantage. The $\Delta \mathrm{F} 508$ is most common in white populations in the United Kingdom, United States, and The Netherlands but has a greatly reduced incidence in southern European populations ${ }^{5}$ and in black and Mongoloid populations. Noticeably, fair skinned people are the most susceptible to melanoma and so would benefit the most from the possibly protective heterozygous state.

Our finding of an inverse association between being a carrier of $\triangle F 508$ and melanoma was unexpected. It suggests that the presence of a genetic marker (or gene defect) may protect against melanoma.

We thank $\mathrm{L}$ Meredith for providing some of the data on normal subjects; P Laidler, J A Whittaker, L Hughes, A
Jacobs, and P Harper for providing clinical samples and useful discussion; and D C Hughes, G Carter, V K Shukla, and C Farr for preparing the DNA samples. This work was funded by the Cancer Research Campaign and Leukaemia Research Fund of Great Britain

1 Rommens JM, Ianuzzi MC, Kerem B, et al. Identification of the cystic fibrosis gene: chromosome walking and jumping. Science 1989;245: 1059-65.

2 McIntosh I, Lorenzo ML, Brock DJH. Frequency of delta F508 mutation on vistic fibrosis chromosomes in UK. Lancet 1989;ii: 1404-5.

3 Al-Jader LN, W'est RR, Goodchild MC, Harper PS. Mortality from leukaemi among relatives of patients with cystic fibrosis. BMJ 1989;298:16t.

4 Al-Jader LN, West RR, Holmes JA, Meredith L, Goodchild MC, Harper PS. Leukacmia mortality among relatives of cystic fibrosis patients. Arch Dis Child 1991:66:317.9.

5 Estivill X, Chillon M, Casals T, et al. Delta F508 gene deletion in cystic fibrosis in southern Europe. Lancet 1989;ii:140.

(Accepted 21 fanuary 1991)

\section{Suicide among men in the highlands of Scotland}

\author{
Iain K Crombie
}

\section{Department of}

Epidemiology and Public

Health, Ninewells Hospital

and Medical School,

Dundee DD1 9SY

Iain K Crombie, PHD, senior lecturer

BMF 1991;302:761-2
Suicide in Scotland has attracted attention because of an unexplained, rapid rise in the rates among men. ${ }^{1} \mathrm{~A}$ recent study found no association between suicide rates and levels of unemployment. ${ }^{2}$ This was unexpected as unemployment is known to be associated with many measures of social deprivation that might themselves be associated with high suicide rates. ${ }^{3}$ I therefore studied the geographical distribution of suicide in Scotland.

\section{Subjects, methods, and results}

Data on deaths from suicide (ICD (ninth revision) codes 950-959), accidental poisoning (ICD codes 850-869), and deaths undetermined, whether accidentally or purposely inflicted (ICD codes 980-989), during 1974-86 for the 56 local government districts were obtained as described previously.' Population data were obtained from the annual report of the registrar general (Scotland) for 1981. Standardised mortality ratios were calculated for each sex as described by Armitage $^{+}$by using five year age specific mortality rates and population data.

A total of 4054 men died by suicide during 1974-86. Standardised mortality ratios for local government districts covered a fivefold range from 39 to 226 (the value for Scotland as a whole is defined as 100). The figure shows that during 1974-86 almost all the highest rates of suicide among men occurred in northern Scotland. All eight districts in the highland region had standardised mortality ratios above 120 , and there were 95 more deaths from suicide than expected in this region. With two exceptions, low rates of suicide were found exclusively in the central belt of Scotland. This distribution was not simply due to chance variation in the rates because the same pattern was found when the districts with appreciably raised or lowered standardised mortality ratios were mapped (data not shown). Furthermore, the pattern was stable over time: when standardised mortality ratios were calculated separately for 1974-9 and 1982-6 six of the highland districts had standardised mortality ratios above 120 for both periods and nine of the central belt districts had standardised mortality ratios below 80 for both periods.

An analysis of the methods of suicide showed that suicides by drowning and hanging followed the gradient for all suicides most closely, but the

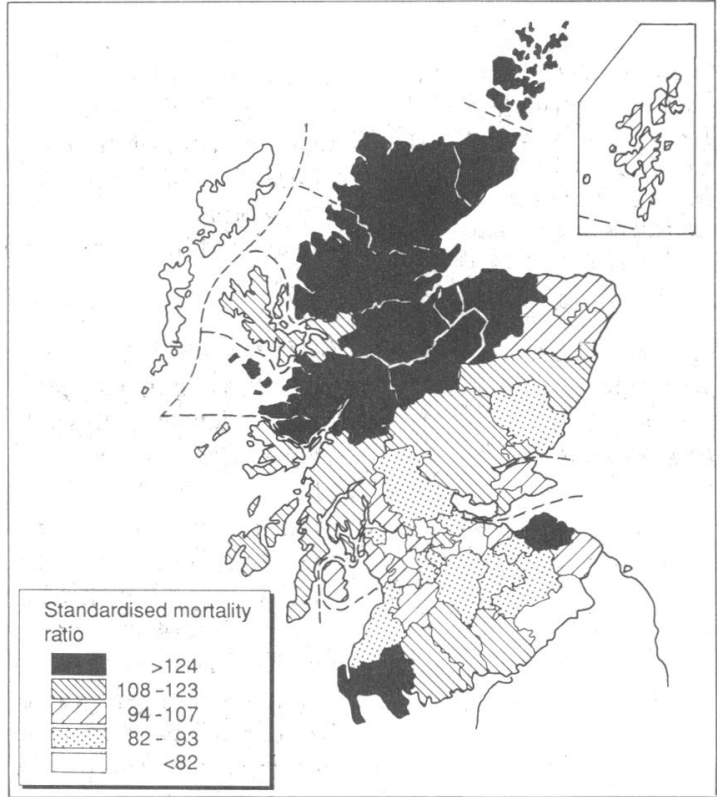

Geographical distribution of mortality from suicide among men in Scotland by local government district during 1974-86. Each range represents a fifth of distribution

pattern for the other methods was inconsistent. The geographical distribution could not be explained by regional differences in notification of suicide: when deaths from accidental poisoning and those that were undetermined were aggregated with the deaths from suicide the pattern was preserved.

The range in standardised mortality ratios for suicide among women (41 to 147) was less than that among men, and the association between the rates in the two sexes was weak (correlation coefficient $\mathrm{r}=0 \cdot 184, \mathrm{p}>0 \cdot 2)$. The geographical distribution of suicide among women was also harder to interpret, partly because their lower mortality rates were subject to much more sampling variation. Thus only three districts had appreciably raised standardised mortality ratios, two in the north of Scotland and one in the central belt. A map of standardised mortality ratios for women confirmed this weak and inconsistent pattern (data not shown).

\section{Comment}

The finding of a cluster of high mortality from suicide among men in the districts in the highlands of Scotland was unexpected. The districts with low mortality were in the central belt of Scotland, which is associated with high population density, heavy industry, and social disadvantage. Mental illness is by 
far the most important risk factor for suicide, ${ }^{5}$ so one possible explanation for these findings would be a regional variation in the incidence of mental illness, particularly among men. Alternatively, the explanation could be sociological, although the factor(s) involved will differ from those associated with inner city deprivation. Certainly, the conventional view of the rural idyll in the Scottish highlands-of contentment and freedom from stress-does not seem to be borne out.
IKC is supported by the Scottish Home and Health Department.

1 McLoone P, Crombie IK. Trends in suicide in Scotland, 1974-84: an increasing problem. $B M \mathcal{F} 1987 ; 295: 629-31$

2 Crombie IK. Trends in suicide and unemployment in Scotland between 1976 and 1986. BMF 1989;298:782-4.

3 Stengel E. Suicide and attempled suicude. Harmondsworth: Penguin, 1973.

4 Armitage P. Statistical methods. Oxford: Blackwell, 1971.

5 Hawton K. Assessment of suicide risk. Br $\mathcal{F}$ Psychiatry 1987; 150:145-53.

(Accepted lo fanuary 1991)

\section{Hormone replacement therapy induced chorea}

\author{
Malcolm J Steiger, Niall P Quinn
}

University Department of Clinical Neurology, Institute of Neurology, London WC1N 3BG

Malcolm J Steiger, MRCP, clinical research fellow

Niall P Quinn, MD, senior lecturer

Correspondence to: Dr Steiger.

BMF 1991;302:762 prescribed hormone replacement therapy.

\section{Case report}

Chorea gravidarum and chorea induced by the contraceptive pill are well recognised, albeit rare, in young women, who often also have a history of Sydenham's chorea in childhood. We report the case of a 57 year old woman who developed reversible chorea when

At the age of 13 years the woman contracted scarlet fever, closely followed by generalised Sydenham's chorea, lasting about six weeks. At around the time of her menarche she developed intermittent, classic migraine attacks with no temporal relation to her menstrual cycle. Her first two pregnancies were uneventful, but her third ended with a miscarriage at 13 weeks. There was no history of venous thrombosis, and she had never taken the contraceptive pill.

At 48 her migraine increased in severity and frequency. She was prescribed ergotamine tartate, cyclizine hydrochloride, and caffeine hydrate (Migril), followed three months later by buclizine hydrochloride, paracetamol, and codeine phosphate (Migraleve). Two weeks later she developed right hemichorea, which reached a peak after six weeks and was considerably improved by the time she was admitted to hospital 10 weeks later. Computed tomography; full blood count; thyroid and liver function tests; copper studies; measurements of erythrocyte sedimentation rate, antistreptolysin $\mathrm{O}$ titre, serum titres of autoantibodies including antinuclear factor, and electrolyte values; and all other investigations gave normal results except that thyroid microsomal antibody titre was 1:400. Syphilis serology gave negative results in blood and cerebrospinal fluid, which showed no abnormality. The chorea was thought to be secondary to consumption of cyclizine or buclizine, or both, and by discharge the following month it had almost disappeared. Her menopause occurred over the ensuing months.

In July 1989 , aged 58 , she was prescribed conjugated oestrogens and norgestrel for vaginal dryness. Within two weeks she again developed right hemichorea. Examination showed chorea of the right arm and leg and of the mouth, as before, with additional slight chorea of the left hand. Reinvestigation showed a normal full blood count, erythrocyte sedimentation rate, and creatine phosphokinase activity and no acanthocytes or autoantibodies, including antinuclear factor. Thyroid function was normal, but the thyroid microsomal antibody titre was 1:6400. Prothrombin time and partial thromboplastin time with kaolin were both normal. Lupus anticoagulant and anticardiolipin IgM and IgG were not detected. Computed tomography showed mild cerebellar atrophy. Hormone replacement therapy was stopped and the chorea began to regress two weeks later, subsiding almost completely over the next four weeks.

\section{Comment}

Chorea induced by oral contraceptives, ${ }^{1}$ chorea gravidarum, ${ }^{2}$ Sydenham's chorea ${ }^{3}$ and lupus chorea are intertwined in published reports. Many women developing chorea with oral contraceptives or chorea gravidarum have a history of alleged Sydenham's chorea. ${ }^{12}$ A few women initially diagnosed as having Sydenham's chorea, however, have lupus or the lupus anticoagulant syndrome. ${ }^{5}$ Moreover, chorea gravidarum may also occur in women with lupus. ${ }^{4}$

In our patient the initial episode of Sydenham's chorea, the onset of migraine, and the menarche were all temporally associated. Chorea did not occur during pregnancy but did recur in the same year as the menopause, which was associated with exacerbation of her migraine. The drug treatment was blamed for the recurrence of chorea, but the hormonal changes associated with the menopause might equally have been responsible.

The administration of hormone replacement therapy was causally related to the appearance of prominent chorea and its withdrawal to noticeable clinical improvement. Despite the history of migraine, one miscarriage, and chorea we have excluded lupus and the lupus anticoagulant syndrome as far as possible. She also had a lifelong tendency to develop mild fidgets at times of stress, and we have never seen her entirely free of involuntary movements. This raises the question of whether persistent rheumatic chorea exists.

To our knowledge there are no reports of chorea provoked by conjugated oestrogens with norgestrel. The prescription of hormone replacement therapy to postmenopausal women is growing. Doctors should be aware that such treatment might provoke chorea, especially in women with a history of Sydenham's chorea.

We thank Dr R A Asherson for helpful advice.

1 Nausieda PA, Koller WC, Weiner WJ, Klawans HL. Chorea induced by oral contraceptives. Neurology 1979;29:1605-9.

2 Willson P, Preece AA. Chorea gravidarum. Arch Intern Med 1932;49:471-533.

3 Nausieda PA, Grossman BJ, Koller WC, Weiner WJ, Klawans HL. Sydenham chorea: an update. Neurology 1980;30:331-4

4 Bruyn GW, Padberg G. Chorea and systemic lupus erythematosus: a critical review. Eur Neurol 1984;23:278-90

5 Bouchez B, Arnott G, Hatron PY, Wattel A, Devulder B. Chorée et lupus érythémateux disséminé avec anticoagulant circulant. Trois cas. Rev Neurol (Paris) 1985;141:571-7.

(Accepted 18 January 199I) 